\title{
Levantamento das espécies de mamíferos não voadores de pequeno porte (roedores e marsupiais) da Serra da Jiboia, Bahia, Brasil
}

\author{
Wallyson Herbet da Silva ${ }^{1}$; Téo Veiga de Oliveira ${ }^{2}$ \\ 1. Bolsista PROBIC, Graduando em Bacharelado em Ciências Biológicas, Universidade Estadual de Feira de \\ Santana, e-mail: wallyson_h2@hotmail.com \\ 2. Orientador, Departamento de Ciências Biológicas, Universidade Estadual de Feira de Santana, e-mail: \\ teovoli@yahoo.com.br
}

PALAVRAS-CHAVE: Mastofauna, Inventário, Serra da Jiboia.

\section{INTRODUÇÃO}

A Serra da Jiboia é uma área que compreende uma porção de Mata Atlântica, localizada no Recôncavo Sul da Bahia. A diversidade de organismos que a habitam é notável e dentre esses organismos estão os mamíferos de pequeno porte, tais como os didelfimorfios, os quirópteros e os roedores. Pequenos mamíferos terrestres estão entre as formas mais diversas de mamíferos no Brasil, mesmo que o número de estudos realizados em algumas partes do país seja muito baixo. Entre as formas mais importantes nas florestas neotropicais estão os didelfimorfios ("marsupiais") e os roedores (Emmons \& Feer, 1997; Reis et al., 2011). Estes animais são muito importantes do ponto de vista ecológico, já que atuam como dispersores de sementes, polinizadores, reguladores das populações de invertebrados e plantas e, além disto, ocupam posições basais na teia trófica, servindo de presas para vertebrados maiores (Cáceres \& Monteiro-Filho, 2000; Terborgh et al., 2001; Reis et al., 2011). Entre os roedores e didelfimorfios que ocorrem na Mata Atlântica, cerca de 30\% e 15\%, respectivamente, são endêmicos dela (Paglia et al., 2012), o que ressalta a importância da continuidade e da intensificação dos estudos neste bioma.

\section{METODOLOGIA}

Armadilhas de captura viva dos tipos Tomahawk e Sherman foram instaladas em padrão de transecção (Auricchio \& Salomão, 2002; Reis et al., 2010) ao longo de trilhas nos dos dois pontos amostrados: Fazenda Baixa de Areia e Reserva Particular do 
Patrimônio Natural. As armadilhas permaneceram ativas durante seis noites consecutivas, sendo revisadas pela manhã. Foram utilizados dois tipos de isca: (1) pedaços de banana e bacon e (2) mistura de paçoca de amendoim, fubá de milho, sardinha e óleo de fígado de bacalhau (Grelle, 2003); caso as iscas estivessem consumidas ou deterioradas foram substituídas por iscas novas. Os indivíduos capturados foram medidos, sendo aferidas as seguintes medidas: comprimento cabeçacorpo, comprimento da cauda, comprimento do pé com e sem garra e comprimento interno da orelha. Os indivíduos também foram pesados e tiveram o sexo determinado. A identificação foi feita através do auxílio de guias de identificação (por exemplo Emmons \& Feer, 1997; Bonvicino et al., 2008; Reis et al., 2011).

\section{RESULTADOS E DISCUSSÃO}

Duas áreas foram amostradas: a Fazenda Baixa de Areia e a RPPN Guarirú, no município de Varzedo. Na Fazenda Baixa de Areia, a amostragem resultou em uma riqueza de quatro espécies e uma abundância total de seis indivíduos: Trinomys setosus $(\mathrm{n}=1)$, Didelphis albiventris $(\mathrm{n}=3)$, Didelphis aurita $(\mathrm{n}=1)$ e Marmosops incanus $(\mathrm{n}=1)$. Quatro recapturas foram reconhecidas, uma vez que os animais foram marcados com brincos de alumínio: Trinomys setosus, Didelphis albiventris, Marmosops incanus, sendo que o primeiro foi recapturado duas vezes. Na RPPN Guarirú, a amostragem resultou em uma riqueza de três espécies, e uma abundância total de três indivíduos: Marmosops incanus $(\mathrm{n}=1)$, Metachirus nudicaudatus $(\mathrm{n}=1)$ e Marmosa murina $(\mathrm{n}=1)$. Não houve recapturas nessa área. As duas amostragens obtiveram resultados positivos. Entretanto a região da Fazenda Baixa de Areia obteve uma riqueza e uma abundância maior que a RPPN Guarirú. A amostragem total resultou em uma riqueza de seis espécies (cinco didelfimorfios e um roedor) e numa abundância total de nove indivíduos. As espécies foram identificadas através de caracteres morfológicos com auxilio de guas de campo, um casal testemunha foi coletado e tombado para a coleção zoológica do Museu de Zoologia da Universidade Estadual de Feira de Santana. O Didelphis albiventris foi a espécie mais abundante na área 1 , mas não houve captura da espécie na área 2, ao realizar a biometria, um brinco de identificação é colocado no individuo, essa técnica permitiu que quatro recapturas fosse identificadas na área 1.

\section{REFERÊNCIAS}


AURICCHIO, P. \& SALOMÃO, M.G. 2002. Técnicas de coleta e preparação de vertebrados para fins científicos e didáticos. São Paulo: Arujá: Instituto Pau Brasil de História Natural. 348p.

BONVICINO, C.R.; OLIVEIRA, J.A. \& D'ANDREA, P.S. 2008. Guia dos Roedores do Brasil, com chaves para gêneros baseadas em caracteres externos. Rio de Janeiro: Centro Pan-Americano de Febre Aftosa - OPAS/OMS.

CÁCERES, N.C \& MONTEIRO-FILHO, E.L.A. 2000. The common opossum, Didelphis aurita, as a seed disperser of several plants in southern Brazil. Cienc. Cult. 52(1):41-44.

CAMPBELL HW, CHRISTMAN SP, 1982. Field techniques for herpetofaunal community analysis. In: Scott-Jr NJ (Eds). Herpetological communities: a Symposium of the Society for the Study of Amphibians and Reptiles and the Herpetologists' League. U.S. Fish Wildlife Service, Washington, USA.

EMMONS, L. \& FEER, F. 1997. Neotropical rainforest mammals. A field guide. Second edition. Chicago: The University of Chicago Press 307p.

GRELLE, C.E.V. 2003. Forest structure and vertical stratification of small mammals in a secondary Atlantic forest, southeastem Brazil. Studies on Neotropical Fauna and Environment. V. 38, p. 81-85.

PAGLIA, A.P., FONSECA, G.A.B. DA, RYLANDS, A. B., HERRMANN, G., AGUiAR, L. M. S., CHIAREllo, A. G., LEITE, Y. L. R., COSTA, L. P., SICILIANO, S., KIERULFF, M. C. M., MENDES, S. L., TAVARES, V. DA C., MITTERMEIER, R. A. \& PATTON J. L. 2012. Lista Anotada dos Mamíferos do Brasil / Annotated Checklist of Brazilian Mammals. 2a Edição / 2nd Edition. Occasional Papers in Conservation Biology, No. 6. Conservation International, Arlington, VA. 76pp.

REIS, N.R.; PERACHI, A.L.; PEDRO, W.A. \& LIMA, I.P. 2011. Mamíferos do Brasil. 2ed. Londrina, 439p.

REIS, N.R.; PERACHI, A. L.; ROSSANEIS, B.K. \& FREGONEZI, M.N. 2010. Técnicas de estudo aplicadas aos mamíferos silvestres brasileiros. Rio de Janeiro: Technical Books, 275p.

TERBORGH, J., LAWRENCE, L., NUÑES, P., RAO M., SHAHABUDDIN, G., ORIHUELA, G.RIVEROS, M., ASCANIO, R. \& ADLER, G.H., 2001. Ecological Meltdown in Pre dator-Free Forest Fragments. Science 294 (5548), 1923-26. 